\title{
DISTRIBUTION OF CULICOIDES HOLLENSIS, C. FURENS AND C. BERMUDENSIS IN RELATION TO PLANT COVER IN A NORTH CAROLINA SALT MARSH (DIPTERA: CERATOPOGONIDAE) ${ }^{1}$
}

\author{
By D. L. Kline ${ }^{2,3}$ and R. C. Axtell ${ }^{2}$
}

\begin{abstract}
The distribution of Culicoides (Diptera: Ceratopogonidae) in relation to plant cover in a North Carolina salt marsh was determined by sticky cylinder traps, emergence traps and soil sampling. All 3 methods showed essentially the same distribution pattern for C. hollensis (Melander \& Brues) and C. furens (Poey) although the former was most abundant in tall ( $>1.2 \mathrm{~m}$ ) Spartina alterniflora Loiseleur (smooth cordgrass) and the latter in short $(<0.3 \mathrm{~m}) S$. alterniflora. These 2 species were rare in the areas of Juncus roemerianus Scheele (black needle rush) and shrubs. $C$. bermudensis Williams was not caught on sticky traps, but the other methods showed that this species was restricted to areas of Distichlis spicata (L.) Greene (salt grass) and J. roemerianus.
\end{abstract}

Salt marshes, which are highly productive systems, have been described (Kraeuter \& Wolf 1974) as

\footnotetext{
${ }^{1}$ This research was supported by NOAA, Office of Sea Grant, U.S. Department of Commerce, under Grant No. 04-3-158-40 and the North Carolina Department of Administration. Paper No. 4735 of the Journal Series of the North Carolina Agricultural Experiment Station.

${ }^{2}$ Department of Entomology, North Carolina State University, Raleigh, NC 27607, U.S.A.

${ }^{3}$ Present address: Biology Department, The Citadel, Charleston, SC 29409, U.S.A.
}

biological continuums between land and estuary. Two of their outstanding characteristics are (1) the universal influence of saline tides and (2) the zonal pattern of plant distribution, influenced by tide elevation (Chapman 1960, Adams 1963, Ranwell 1972). These beds of intertidal rooted vegetation are inundated and drained by the rise and fall of the tide, a process which ties the marshland to the estuary with an exchange of nutrients and organic matter (Cooper 1974).

This tide-stressed environment exerts a strong selective control over the kinds of species present. The same genera of grasses and rushes, and animals, such as fiddler crabs, are encountered repeatedly in widely separated geographic regions (Chapman 1960, Cooper 1974). Biting flies of the genus Culicoides are found in this habitat in the United States (Dove et al. 1932, Jamnback et al. 1958, Wall \& Doane 1960, Jamnback 1965, Hair et al. 1966, Cameron 1972, Wall 1973, Kline and Axtell 1976) 
and elsewhere (Kettle \& Lawson 1952, Forratini et al. 1958, Becker 1961). However, the distribution of larvae and adults within a marsh is poorly known.

Therefore, this investigation was conducted in 1972 and 1973 to determine the distribution of Culicoides within a North Carolina salt marsh in relation to the plant cover.

\section{MATERIALS AND METHODS}

Study site

The study site was a portion of a salt marsh (diagramed and described in Dukes et al. 1974) along the Newport River, Morehead City, Carteret

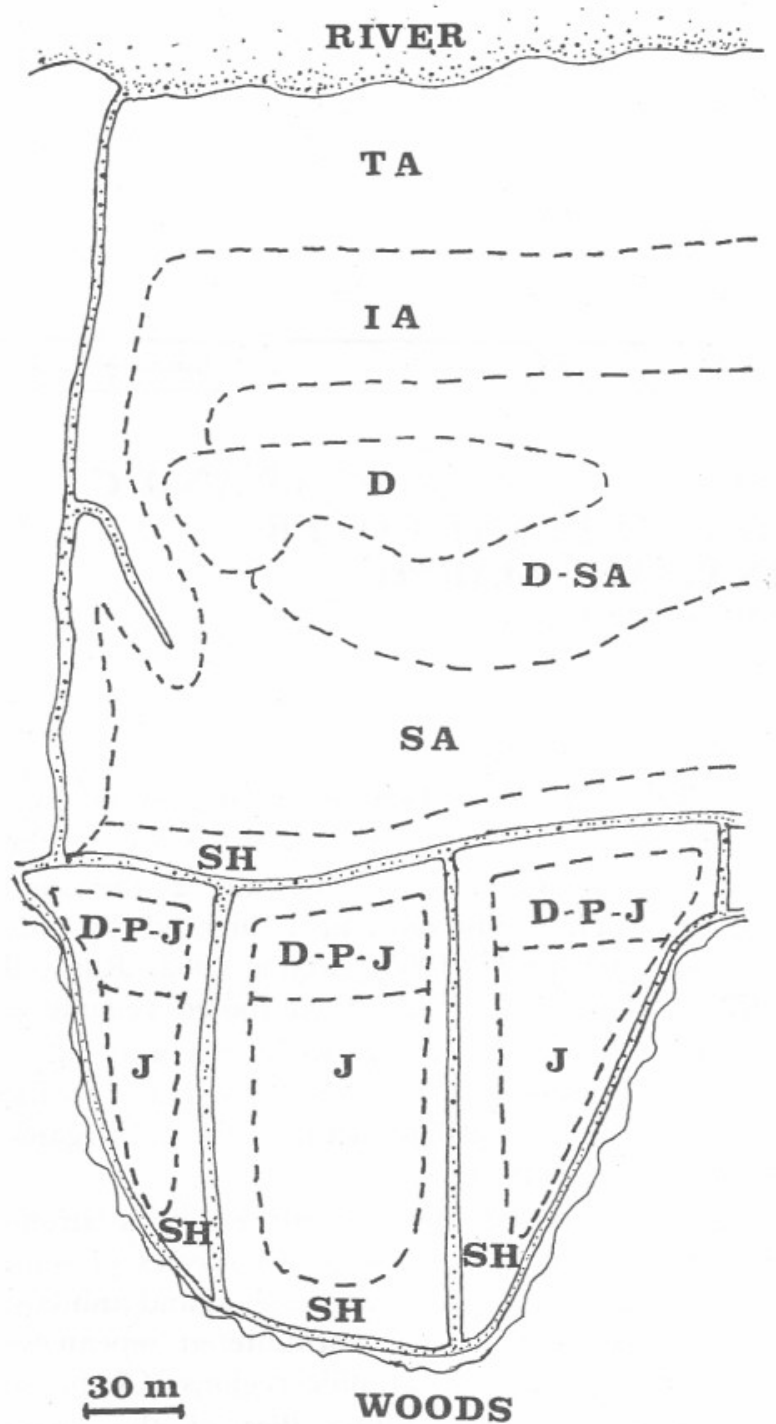

FIG. 1. Simplified diagram of vegetative zones in study area $\mathrm{B} . \mathrm{TA}=$ tall Spartina alterniflora, $\mathrm{IA}=$ intermediate Spartina alterniflora, $\mathrm{SA}=$ short Spartina alterniflora, $\mathrm{D}=$ Distichlis spicata, $\mathrm{P}=$ Spartina patens, $\mathrm{J}=$ Juncus roemerianus, $\mathrm{SH}=$ shrubs.
County, North Carolina. Two study areas were selected within this site and the plant cover was carefully mapped. The most common plant species, Spartina alterniflora Loiseleur (smooth cordgrass), consisted of 3 forms: a tall form ( $>1.2 \mathrm{~m})$, an intermediate form $(0.3-1.2 \mathrm{~m})$ and a short form $(<0.3 \mathrm{~m})$.

Study area A was a portion of the marsh consisting of intermediate form $S$. alterniflora, with tall form $S$. alterniflora in a $10-12 \mathrm{~m}$ band along a manmade ditch (15-18 $\mathrm{m}$ wide) and a 1-2 $\mathrm{m}$ band along a natural ditch. In the nearby study area $\mathrm{B}$, the salt marsh plants occurred in zones of nearly pure stands and mixed vegetation at the interfaces (FIG. 1). The major vegetative zones (in order from the river to the upland) were as follows: tall form $S$. alterniflora, intermediate form S. alterniflora, Distichlis spicata (L.) Greene (salt grass), short form $S$. alterniflora, Juncus roemerianus Scheele (black needle rush) and mixed shrubs and small trees [Baccharis halimifolia L., Borrichia frutescens (L.) Dc., Ilex vormitorea Ait., Iva imbricata Walt., Myrica cerifera L. and Pinus taeda L.]. The portion of the marsh nearest the upland consisted of $J$. roemerianus and several man-made drainage ditches (1-2 m wide) which were bordered by shrubs on spoil piles. The adjacent upland was a mixed pine-deciduous woods dominated by $P$. taeda, Cornus florida Linnaeus, and Wisteria sinensis (Sims) Sweet.

\section{Sampling methods and trap arrangement}

Sticky cylinder traps, emergence traps, and soil samples were used to determine the abundance of Culicoides in the various vegetative habitats within the marsh. The sticky cylinder traps (Kettle 1951) captured adult gnats as they flew from the surrounding larval habitats. Traps were made from cylinders $(30.5 \mathrm{~cm}$ high $\times 10.2 \mathrm{~cm}$ diam. $)$ of black plastic sewer pipe attached to black-painted wooden posts $(2.4 \mathrm{~m} \times 2.5 \mathrm{~cm} \times 2.5 \mathrm{~cm})$. Each trap consisted of 3 cylinders placed with centers $0.6 \mathrm{~m}$, $1.2 \mathrm{~m}$ and $1.8 \mathrm{~m}$ above ground level. The $1.8-\mathrm{m}$ level was used continuously; the other 2 levels were used at peak periods to determine whether adults had any height preference within or between vegetative types. Adult Culicoides were captured on a sheet of cellulose acetate that was thinly coated (by means of a small paint roller) with Bird Tanglefoot ${ }^{\circledR}$ (Tanglefoot Co., Grand Rapids, Michigan) wrapped around the outside of the cylinder and attached with metal clips. Once a week the acetate sheets were replaced. The specimens were removed from the sheets with petroleum solvent, rinsed in naphtha and preserved in $70 \%$ ethyl alcohol for 
subsequent identification.

In 1972, 18 sticky cylinder traps were arranged in area $\mathrm{B}$ in parallel transects $(30 \mathrm{~m}$ apart) with 3 traps in each of the following 6 vegetative zones: (1) intermediate $S$. alterniflora, (2) short $S$. alterniflora, (3) D. spicata, (4) mixed stand of D. spicata, J. roemerianus and Spartina patens (Ait.) Muhl. (salt meadow grass), (5) J. roemerianus, and (6) marsh shrubs (on spoil piles along drainage ditches adjacent to the upland). In 1973, 6 traps were used in 2 vegetative zones: the same 3 in the short form $S$. alterniflora and 3 new traps placed $30 \mathrm{~m}$ apart in the tall form $S$. alterniflora along the large manmade drainage ditch in area A.

Emergence traps (Davies 1966, Linley et al. 1970) caught the adult gnats as they emerged from the soil beneath. Each trap consisted of a cone of galvanized metal $(63.5 \mathrm{~cm}$ diam. at the base and $48.3 \mathrm{~cm}$ high) with a $5.1-\mathrm{cm}$ diam. hole at the apex, around which a $2.5-\mathrm{cm}$ band of galvanized metal was soldered to hold (by means of sheet metal screws) a polypropylene plastic jar lid with a 5.1-mm diam. hole in the center. The threaded plastic lid held a standard glass pint (0.48-liter) jar in the inverted position over the opening at the apex of the cone. Plastic lids were used because standard metal ones deteriorated rapidly in the marsh environment. The inside of each jar was lined with a strip $(10.2 \mathrm{~cm} \times 20.3 \mathrm{~cm})$ of transparent cellulose acetate which was thinly coated (using a small paint roller) with Tanglefoot. A thin layer of Tanglefoot was also brushed onto the inner lip and inside bottom of the jar. Adult Culicoides which emerged from the soil were attracted upwards by the light and adhered to the sticky surfaces. Specimens were removed for subsequent identification and counting by rinsing the jar and acetate strip with petroleum solvent.

In 1972, 20 emergence traps were operated (mostly from March to mid-Nov.) in the various vegetative zones. In area $\mathrm{B}$, the traps were in 2 parallel transects from the river to the upland in the following types of vegetation: (1) tall $S$. alterniflora (river's edge), (2) intermediate S. alterniflora, (3) D. spicata, (4) short $S$. alterniflora, (5) J. roemerianus, and (6) shrubs. There were 4 traps in the zones of $D$. spicata and $J$. roemerianus and 2 in each of the other zones. Additional traps were placed in tall S. alterniflora: 2 along the natural ditch in area B and 2 along the man-made ditch in area A. In 1973, 32 emergence traps were operated from March to mid-Nov. in the same plant zones listed above. In area $\mathrm{B}$, the traps were in 2 parallel transects from the river to the upland with 4 traps in each of the 6 vegetative zones. Additional traps were placed in tall $S$. alterniflora: 4 along the natural ditch in area B and 4 along the man-made ditch in area A. In both years the traps were moved about $1 \mathrm{~m}$ twice weekly in a clockwise pattern to minimize bias due to the possibility (suggested by Davies 1966) that larvae would be attracted from the surrounding area to the soil beneath the trap. Jars were changed twice each week in 1972 and once each week in 1973.

Soil samples for recovery of Culicoides larvae were taken at least once a month in 1973 (MarchDecember, omitting April). Along each of 2 transects in area $\mathrm{B}, 16$ sampling sites were used with each of the following vegetative areas represented: (1) tall $S$. alterniflora (river's margin), (2) intermediate $S$. alterniflora, (3) D. spicata, (4) mixed $D$. spicata and short $S$. alterniflora, (5) short $S$. alterniflora, (6) J. roemerianus and (7) marsh shrubs (small ditch and spoil piles). One of the transects was sampled first in March and the other initially in June. In addition, in May-December, samples were taken monthly from each of the 2 transects in tall and in intermediate $S$. alterniflora along the man-made drainage ditch in area $\mathrm{A}$.

Each soil sample was taken (after cutting and removing the vegetation) with a post-hole digger, which yielded a core ca $7.6 \mathrm{~cm}$ diam. and $10 \mathrm{~cm}$ deep. Sampling was during a 2-hr period at low tide. Each sample was washed with water through 10- and 40-mesh screens to separate mud and vegetation. The residue retained on the 40-mesh screen was placed in a 1-liter cylinder which was then filled with saturated magnesium sulfate solution, stirred and allowed to stand for $10 \mathrm{~min}$. for the inorganic matter to settle to the bottom. The Culicoides larvae floated to the surface where they were removed with a pipette. When all visible larvae were removed, the mixture was restirred, allowed to settle, and visible larvae again removed. This process was repeated until no larvae were observed in 3 successive attempts.

Except for early samples, the majority of extracted larvae were reared (Linley 1968) to the adult stage for identification. Rearing dishes were clear plastic containers $15.2 \mathrm{~cm}$ wide and $3.8 \mathrm{~cm}$ deep, with tight-fitting lids that contained a hole, closed with a cork, for adding food and another hole covered with 40 -mesh brass screening for air exchange. The dishes were kept in a rearing chamber at $26.7 \pm$ $1{ }^{\circ} \mathrm{C}$. The rearing medium was damp mud taken from an area adjacent to the marsh and known (by periodically washing several samples) not to contain any Culicoides larvae. The mud was mixed 
in a large container to insure that the medium was uniform among the dishes. As an added precaution, a dish containing only mud was used as a control each time. Nematodes, reared on oatmeal, were added every other day to each dish. The dishes were opened daily inside a large cage, and any adult Culicoides which were present were collected by aspirator.

The various vegetative zones were characterized in terms of plant species and height, percentage time flooded, and chemical properties of the soil. The average percentage time flooded per year was calculated by using a surveyor's transit to determine the elevation of each position in relation to levels on a tide gauge recorder (Leupold-Stevens Type F), which continuously recorded tide level. Samples of soil to a depth of $10 \mathrm{~cm}$ from 2 locations in each vegetative zone were analyzed (by the Soil Testing Division, North Carolina Department of Agriculture, using routine methods) for phosphorous, potassium, calcium, magnesium, sodium, $\mathrm{pH}$ exchangeable acidity, manganese, soluble salts, nitrate-nitrogen, zinc and organic matter.

\section{Statistical analyses of data}

The SAS ANOVA procedure (Service 1972) was used to analyze the 1972 data from the sticky cylinder traps and the 1973 emergence traps. Means were compared by Duncan's multiple range test. The 1972 emergence traps were operated for unequal periods of time and therefore analysis of variance was not performed. Data from the soil samples were analyzed by multiple linear regression procedures to correlate the total larvae recovered (all species combined) and the number of adults of each species emerging with the percentage time the marsh site was flooded, and with the soil characteristics. Four techniques (forward selection, backward elimination, stepwise, and maximum $\mathrm{R}^{2}$ improvement) were used to test for significant correlations (Service 1972).

\section{RESULTS}

Sticky cylinder traps: The catches on sticky traps in 1972 showed that both Culicoides hollensis and Culicoides furens occurred throughout the marsh (TABle 1). C. hollensis was less abundant than $C$. furens, and no Culicoides bermudensis were captured on these traps. C. hollensis was almost uniformly distributed among the various vegetative zones within the marsh. C. furens was most abundant in the short form Spartina. The lowest number of both species were from the traps located in areas of $J$. roemerianus, shrubs, and mixed stands of $D$. spicata,
TABLE 1. Collections of adult Culicoides on sticky cylinder traps (1.8 $\mathrm{m}$ above the ground) located in various plant zones in a salt marsh (1972).

\begin{tabular}{lcc} 
& \multicolumn{2}{c}{$\begin{array}{c}\text { MEAN NO./TRAP/ } \\
\text { WEEK* }\end{array}$} \\
\cline { 2 - 3 } VEgetation & C. hollensis & C. furens \\
\hline Intermediate Spartina alterniflora & $6.6 \mathrm{a}$ & $27.9 \mathrm{~b}$ \\
Short Spartina alterniflora & $6.9 \mathrm{a}$ & $50.9 \mathrm{a}$ \\
Distichlis spicata & $5.2 \mathrm{ab}$ & $20.1 \mathrm{~b}$ \\
Mixed Distichlis spicata, Spartina patens & & \\
$\quad$ and Juncus roemerianus & $4.7 \mathrm{ab}$ & $18.1 \mathrm{bc}$ \\
Juncus roemerianus & $5.0 \mathrm{ab}$ & $6.6 \mathrm{c}$ \\
Shrubs & $3.3 \mathrm{~b}$ & $7.3 \mathrm{c}$ \\
\hline
\end{tabular}

*Within each species, the means followed with a common letter are not significantly different at the 0.05 level (Duncan's multiple range test).

$J$. roemerianus and $S$. patens. There were no significant differences among the 3 transects.

In 1973, the mean number gnats captured/trap/ week for $C$. hollensis was 15.4 and 8.3, respectively, for the traps located in the tall and short forms of $S$. alterniflora. For $C$. furens, the mean numbers were 28.9 and 53.4, respectively, for the same 2 areas. This confirmed that both species were abundant in areas of $S$. alterniflora and further demonstrated that $C$. hollensis was most abundant in the areas of the tall form and $C$. furens was most abundant in areas of the short form.

Trap height significantly affected the collections of C. hollensis but not C. furens (TABLE 2). The greatest total number of $C$. hollensis was collected at the trap height of $0.6 \mathrm{~m}$ and this was due to the significantly greater number of males trapped at that height.

Emergence traps: C. hollensis and C. furens were collected in emergence traps throughout the marsh (TABLE 3), while C. bermudensis was collected only from the traps in areas of $D$. spicata and $J$. roemerianus. In $1972,70 \%$ of the $C$. hollensis were recovered from the emergence traps located within the tall $S$. alterniflora along the large man-made drainage ditch and the river and from the intermediate $S$. alterniflora. Intermediate numbers were recovered from the tall $S$. alterniflora along the natural drainage

TABLE 2. Collections of Culicoides hollensis and $C$. furens in a salt marsh at 3 heights of sticky cylinder traps (1972).

\begin{tabular}{|c|c|c|c|c|c|c|}
\hline \multirow{3}{*}{$\begin{array}{l}\text { HEIGHT } \\
\text { (m) }\end{array}$} & \multicolumn{6}{|c|}{ MEAN NO. ADULTS/TRAP/WEEK* } \\
\hline & \multicolumn{3}{|c|}{ C. hollensis } & \multicolumn{3}{|c|}{ C. furens } \\
\hline & $\hat{\sigma}$ & 우 & Total & $\sigma$ & 우 & Total \\
\hline 0.6 & $5.2 \mathrm{a}$ & $8.4 \mathrm{a}$ & $13.6 \mathrm{a}$ & $9.7 \mathrm{a}$ & $23.0 \mathrm{a}$ & $32.7 \mathrm{a}$ \\
\hline 1.2 & $0.9 \mathrm{~b}$ & $8.3 \mathrm{a}$ & $9.2 \mathrm{~b}$ & $8.5 \mathrm{a}$ & $18.1 \mathrm{a}$ & $26.6 \mathrm{a}$ \\
\hline 1.8 & $0.6 \mathrm{~b}$ & $9.3 \mathrm{a}$ & $9.9 \mathrm{~b}$ & $11.1 \mathrm{a}$ & $20.6 \mathrm{a}$ & $31.8 \mathrm{a}$ \\
\hline
\end{tabular}

*The means with a common letter for each species and sex (i.e., in each column) are not significantly different at the 0.05 level (Duncan's multiple range test). 
ditches, short $S$. alterniflora and D. spicata subbabitats. Very few were recorded from the $J$. roemerianus and shrub subhabitats.

In 1973, most (ca $65 \%$ ) of the C. hollensis were recovered from the same Spartina subhabitats: tall form $S$. alterniflora along the man-made ditch and the river and intermediate $S$. alterniflora. The combined lower percentage from these 3 subhabitat: in 1973 compared to 1972 was due to less being obtained from along the man-made ditch and intermediate $S$. alterniflora. While an increased percentage was recovered from short $S$. alterniflora, the percentage from tall $S$. alterniflora along the natural drainage ditches and D. spicata subhabitats remained approximately the same as in 1972. Again, the $J$. roemerianus and shrub habitats were the least productive.

An analysis of variance of the 1973 data showed that the various vegetative subhabitats had a highly significant $(\mathrm{p}<0.0001)$ influence on the distribution of $C$. hollensis. The mean number recovered from tall $S$. alterniflora along the man-made ditch and the river's edge was significantly greater than the numbers recovered from the other subhabitats.

In 1972, the greatest recovery of $C$. furens (TABLE 3) was from short $S$. alterniflora and D. spicata. Fairly large numbers were also taken from tall $S$. alterniflora along the natural drainage ditch and from intermediate and tall $S$. alterniflora near the river's margin. Few were collected from shrub or $J$. roemerianus subhabitats. The fewest were obtained from tall $S$. alterniflora along the man-made drainage ditch.

Similarly, in 1973 the greatest recovery of $C$. furens was from short $S$. alterniflora. However, in 1973 there were more obtained from intermediate and tall forms of $S$. alterniflora near the river's margin than from the D. spicata subhabitat. A fairly large percentage was recovered from tall $S$. alterniflora along natural drainage ditches. Very few were recovered from $J$. roemerianus, shrubs, and tall $S$. alterniflora along the man-made ditch.

An analysis of variance showed that the various vegetative subhabitats had a significant $(\mathrm{p}<0.0001)$ influence on the distribution of $C$. furens. The numbers of $C$. furens recovered from short, intermediate, and tall $S$. alterniflora from near the river were significantly greater than from the other subhabitats, with the short Spartina producing the greatest number.

Soil sampling: The average number of larvae/ sample recovered from the soil obtained from the tall and intermediate $S$. alterniflora subhabitats was greater than that from the other subhabitats (TABLE 4 ); the highest was from samples taken from the tall $S$. alterniflora near the river's edge. Fewer larvae/ sample were recovered from positions dominated by short $S$. alterniflora, $D$. spicata, and the transition zone between them. The fewest were removed from the shrub and $J$. roemerianus subhabitats.

Adult Culicoides emerged from all the rearing dishes containing larvae recovered from soil samples and subsequently held for emergence. All the adult C. bermudensis were found (TABLE 4) in the rearing dishes containing larvae recovered from soil samples obtained from the D. spicata, transition D. spicata-

TABLE 3. Number and percentage (in parentheses) of Culicoides hollensis and $C$. furens caught in emergence traps in various plant zones in a salt marsh.

\begin{tabular}{|c|c|c|c|c|}
\hline \multirow[b]{3}{*}{ VEGETATION } & \multicolumn{4}{|c|}{ MEAN NO. ADULTS/TRAP/WEEK* } \\
\hline & \multicolumn{2}{|c|}{ C. hollensis } & \multicolumn{2}{|c|}{ C. furens } \\
\hline & 1972 & 1973 & 1972 & 1973 \\
\hline Tall Spartina alterniflora, man-made ditch & $\begin{array}{c}28.6 \\
(33.1)\end{array}$ & $\begin{array}{l}25.8 \mathrm{a} \\
(31.9)\end{array}$ & $\begin{array}{c}0.7 \\
(1.9)\end{array}$ & $\begin{array}{l}4.2 \mathrm{~d} \\
(4.4)\end{array}$ \\
\hline Tall $S$. alterniflora, natural drainage ditch & $\begin{array}{c}6.5 \\
(7.5)\end{array}$ & $\begin{array}{l}7.2 \mathrm{~cd} \\
(8.9)\end{array}$ & $\begin{array}{c}3.9 \\
(10.7)\end{array}$ & $\begin{array}{l}8.6 \mathrm{~d} \\
(9.0)\end{array}$ \\
\hline Tall $S$. alterniflora, river's margin & $\begin{array}{c}15.9 \\
(18.4)\end{array}$ & $\begin{array}{l}17.2 \mathrm{~b} \\
(21.2)\end{array}$ & $\begin{array}{c}3.5 \\
(9.6)\end{array}$ & $\begin{array}{l}13.5 \mathrm{c} \\
(14.1)\end{array}$ \\
\hline Intermediate $S$. alterniflora & $\begin{array}{c}16.0 \\
(18.5)\end{array}$ & $\begin{array}{c}9.5 \mathrm{c} \\
(11.8)\end{array}$ & $\begin{array}{c}4.6 \\
(12.4)\end{array}$ & $\begin{array}{l}18.1 \mathrm{~b} \\
(19.1)\end{array}$ \\
\hline Short $S$. alterniflora & $\begin{array}{c}7.6 \\
(8.8)\end{array}$ & $\begin{array}{c}9.4 \mathrm{c} \\
(11.6)\end{array}$ & $\begin{array}{c}12.2 \\
(32.8)\end{array}$ & $\begin{array}{l}33.9 \mathrm{a} \\
(35.8)\end{array}$ \\
\hline Distichlis spicata & $\begin{array}{c}7.9 \\
(9.2)\end{array}$ & $\begin{array}{l}6.9 \mathrm{~cd} \\
(8.5)\end{array}$ & $\begin{array}{c}8.3 \\
(22.2)\end{array}$ & $\begin{array}{l}7.7 \mathrm{~d} \\
(8.1)\end{array}$ \\
\hline Juncus roemerianus & $\begin{array}{l}3.2 \\
(3.7)\end{array}$ & $\begin{array}{l}3.6 \mathrm{~cd} \\
(4.4)\end{array}$ & $\begin{array}{c}1.4 \\
(3.7)\end{array}$ & $\begin{array}{l}4.5 \mathrm{~d} \\
(4.8)\end{array}$ \\
\hline Marsh shrubs & $\begin{array}{c}0.7 \\
(0.8)\end{array}$ & $\begin{array}{l}1.4 \mathrm{~d} \\
(1.7)\end{array}$ & $\begin{array}{c}2.5 \\
(6.8)\end{array}$ & $\begin{array}{l}4.4 \mathrm{~d} \\
(4.7)\end{array}$ \\
\hline
\end{tabular}

*Within each species the means with a common letter are not significantly different at the 0.05 level (Duncan's multiple range test). There were 2-4 traps per plant zone for varying portions of 1972 and 4 traps per plant zone in 1973. 
TABLE 4. Recovery of Culicoides larvae from soil in various plant zones in a salt marsh (1973).

\begin{tabular}{|c|c|c|c|c|c|c|c|}
\hline \multirow[b]{2}{*}{ VEGETATION } & \multirow{2}{*}{$\begin{array}{c}\% \text { TIME } \\
\text { FLOODED }\end{array}$} & \multirow{2}{*}{$\begin{array}{c}\text { No. } \\
\text { SAMPLES }\end{array}$} & \multirow{2}{*}{$\begin{array}{l}\text { AVG. No. } \\
\text { LARVAE/ } \\
\text { SAMPLE }\end{array}$} & \multirow{2}{*}{$\begin{array}{c}\text { No. LARVAE } \\
\text { HELD FOR } \\
\text { EMERGENCE }\end{array}$} & \multicolumn{3}{|c|}{ No. ADULTS EMERGED/LARVA HELD } \\
\hline & & & & & C. bermudensis & C. hollensis & C. furens \\
\hline $\begin{array}{l}\text { Tall Spartina alterniflora, } \\
\text { river's margin }\end{array}$ & $\begin{array}{c}19 * \\
(8-35)\end{array}$ & 48 & 45.3 & 1559 & 0.00 & 0.46 & 0.15 \\
\hline $\begin{array}{l}\text { Tall S. alterniflora, man- } \\
\text { made ditch }\end{array}$ & $\begin{array}{c}36 \\
(26-46)\end{array}$ & 38 & 29.2 & 653 & 0.00 & 0.57 & 0.13 \\
\hline $\begin{array}{l}\text { Intermediate } S \text {. alterniflora, } \\
\text { man-made ditch }\end{array}$ & $\begin{array}{l}15 \\
(5-32)\end{array}$ & 34 & 25.6 & 641 & 0.00 & 0.37 & 0.13 \\
\hline $\begin{array}{l}\text { Intermediate } S \text {. alterniflora, } \\
\text { interior marsh }\end{array}$ & $\begin{array}{l}15 \\
(5-25)\end{array}$ & 48 & 20.3 & 659 & 0.00 & 0.33 & 0.26 \\
\hline Short $S$. alterniflora, & $\begin{array}{l}13 \\
(5-21)\end{array}$ & 49 & 14.7 & 475 & 0.00 & 0.20 & 0.27 \\
\hline $\begin{array}{l}\text { D. spicata }+ \text { short } S \text {. } \\
\text { alterniflora }\end{array}$ & $\begin{array}{ll}11 \\
(0-26)\end{array}$ & 49 & 18.0 & 528 & 0.41 & 0.14 & 0.31 \\
\hline Distichlis spicata & $\begin{array}{c}6 \\
(0-19)\end{array}$ & 48 & 10.9 & 263 & 0.99 & 0.17 & 0.27 \\
\hline Juncus roemerianus & $\stackrel{8}{8}$ & 48 & 7.7 & 180 & 0.72 & 0.23 & 0.27 \\
\hline Shrubs, ditch spoil pile & $\begin{array}{c}12 \\
(3-27)\end{array}$ & 94 & 8.6 & 611 & 0.00 & 0.26 & 0.16 \\
\hline
\end{tabular}

*Avg. $\%$ time covered with water during the year. Values in parentheses are ranges of averages of $\%$ time per week during this study (March-December).

short S. alterniflora, and $J$. roemerianus subhabitats; all the adults were females. $C$. hollensis and $C$. furens adults were found in all rearing dishes. However, based on the number of adults emerging/ larva held for emergence, $C$. hollensis was most abundant in soil samples from areas of tall $S$. alterniflora (river's edge and man-made ditch) and slightly less numerous in areas of intermediate height $S$. alterniflora, while $C$. furens was most abundant in the interior of the marsh in areas of intermediate height $S$. alterniflora, $D$. spicata, transition zones between the 2 areas and in short $S$. alterniflora.

The total number of larvae (combined for all species) recovered from soil samples was significantly correlated ( 0.05 level) with the amounts of calcium, manganese and soluble salts in the soil and with the percentage time the sample area in the marsh was flooded. Other factors were not significant. The 4 multiple regression procedures gave the same result. However, analysis of the data for each species by means of the 4 regression procedures used yielded inconsistencies among the results. Different procedures gave different significant correlations, with the exception that $C$. furens was significantly correlated $(0.05$ level) with frequency of flooding in all cases. Covariance analysis showed that several factors assumed to be independent were, in fact, correlated and thus their effects could be confounded. For example, phosphorous was correlated with manganese, nitrate-nitrogen, organic matter, and percentage time a marsh area was flooded.

\section{DISCUSSION AND CONCLUSIONS}

A consistent pattern of distribution for $C$. hollensis and $C$. furens was revealed by the 3 sampling methods. Both species were distributed throughout the marsh, but $C$. hollensis was most abundant in the tall $S$. alterniflora along the large man-made drainage ditch and the river's edge, and $C$. furens was most abundant in short $S$. alterniflora. The intermediate $S$. alterniflora subhabitat appeared equally favored by both $C$. hollensis and $C$. furens. Based on the combined 1972 and 1973 emergence trap data, the C. hollensis: C. furens ratio was about 4:1 in tall form $S$. alterniflora (man-made drainage ditch and river's edge), approximately $1: 3$ in short $S$. alterniflora, and about 1.5: 1 in intermediate $S$. alterniflora. Neither species was very abundant in the J. roemerianus and marsh-shrubs areas.

In 1972, in cases where sticky cylinder traps and emergence traps were operated near each other in the same habitat, the 2 methods yielded essentially the same data on the distribution patterns of $C$. hollensis and $C$. furens. Thus, we assumed that if sticky traps had been placed either near the river's edge, or along the man-made ditch, the greatest numbers of $C$. hollensis would have been obtained. To check this assumption, in 1973 we kept 3 traps in the short $S$. alterniflora and added 3 traps in the tall $S$. alterniflora along the large man-made ditch. As expected, substantially greater numbers of $C$. hollensis were captured in tall than in short $S$. alterniflora and vice versa for $C$. furens. The sticky cylinders are a convenient means for locating 
breeding centers of certain, but not all, species. C. bermudensis does not come to them. Kettle (1951) used these traps to locate the breeding center of Culicoides impunctatus Goetghebuer. The sticky cylinders do not always adequately reflect the population level, however. We noted that while $C$. furens was very abundant on these sticky traps, C. hollensis was lower than expected.

When compared to the data from the other methods, the differences in the numbers of $C$. furens adults emerging/larva held for the various habitats were smaller than expected. A significantly greater number of adult $C$. furens would be expected in rearing dishes containing larvae obtained from short $S$. alterniflora than from other vegetative types. This was not the case and was probably due to the vegetative debris from the habitat interferring with larval recovery in the sieve-flotation method we used. Greater numbers of $C$. furens would have been obtained by the sand-flotation procedure, according to a subsequent study on the relative efficiency of sampling methods (Kline et al. 1975).

Our data are in general agreement with previous findings of the breeding habitats of $C$. hollensis. Jamnback et al. (1958) reported that C. hollensis larvae were most abundant in areas ". . . where long $S$. alterniflora is the predominant cover."

Linley \& Davies (1971) reported that the larval habitat range of $C$. furens is extensive, but certain basic conditions are always present. Typically the species is a coastal, brackish-water breeder and the larvae are found in wet or damp saline soil, but not in soil permanently inundated. Mangrove swamps, salt marshes, and the banks of ditches are the most frequently reported habitat for this species (Rogers 1962, Linley et al. 1970), but Williams (1964) reported C. furens from fresh-water habitats. We have also found it in sandy intertidal habitats (Kline \& Axtell 1975) but not as abundant as in short $S$. alterniflora, which is a more typical $C$. furens habitat.

C. bermudensis was not caught on the sticky cylinder traps. Based on the recovery of adults from emergence traps and larvae from soil samples, it was restricted to areas of the marsh covered by $D$. spicata, $D$. spicata-short $S$. alterniflora mixtures and $J$. roemerianus. These areas were flooded only $6.4 \%$ to $11.4 \%$ of the time. This species has previously been recovered in salt marsh sod beneath $S$. alterniflora (2 female specimens reared by Jamnback 1965), the margins of salt water pools (Jones 1961) and in Bermuda from marsh soil with a wide variety of plant associations and the salinity ranging from 1.2 to 15 parts per thousand (Williams 1957).
While rearing larvae, we noted that the rearing dishes containing larvae recovered from soil samples obtained from the Distichlis and Juncus areas yielded more adults than the number of larvae originally added to the mud in the dishes. Also, the recovery of adults in relation to the number of larvae added was high with the larvae from the transition $D$. spicata-short $S$. alterniflora areas. Because these larvae were from the only areas from which we recovered $C$. bermudensis, these unusual results were attributed to that species. Williams (1961) reported that this species was both autogenous and parthenogenic (obligate thelytoky) in Bermuda. We considered that our results might be due to autogeny, since our procedures make it possible for newly emerged adults to lay a few eggs before their removal. This would require that the female emerge and deposit her eggs very rapidly (in less than 2 days). If that did occur, there should have been a time gap between completion of emergence of adults from the original larvae and the emergence of the adults derived from eggs laid in the container. This did not happen; only 1 brood emerged and all within a span of 1 week. Thus, autogeny does not appear to be an explanation. Nor do we feel that it was due to contaminated breeding media, since this would have affected all the rearing dishes and no adults emerged from the control dishes. The data suggest, but do not prove, the occurrence of paedogenesis, but this biological phenomenon is rare among Diptera (Wyatt 1961). Further investigations are needed on the biology of $C$. bermudensis.

Several factors appear to influence the distribution of Culicoides within a salt marsh. These include type of vegetation, percentage of time the marsh is flooded and characteristics of the soil. Many of these factors appear to be correlated with each other. For example, vegetative zonation in salt marshes has been correlated with elevation and the amount of tidal inundation to which a particular area is subjected (Chapman 1960, Adams 1963). Tideelevation relationships obviously affect many soil physical and chemical properties which, in turn, influence plant growth (Broome et al. 1973). C. bermudensis was found only in the $D$. spicata, transition $D$. spicata-short $S$. alterniflora, and $J$. roemerianus zones where the average percentage time inundated was from $6 \%$ to $12 \%$; C. hollensis was most abundant in tall S. alterniflora areas which were inundated on the average $19 \%$ to $36 \%$ of the time, and $C$. furens in short $S$. alterniflora areas which were inundated about $13 \%$ of the time. Analysis showed the distribution of Culicoides larvae (all species) and of $C$. furens are correlated with the percentage of 
time of flooding, but correlations with other factors could not be consistently demonstrated. A more intensive study of the soil chemistry in relation to numbers of Culicoides is needed. Also, other factors which may influence larval distribution should be considered. These may include pbysical properties of the substrate, such as soil particle size and density of root structure, as well as food, competition and natural enemies.

Note added to proof: The following review article on coastal Ceratopogonidae has appeared since submission of this paper-Linley, J.R. 1976. Biting midges of mangrove swamps and saltmarshes (Diptera: Ceratopogonidae). p. 335-76 (Chap. 13). In: Cheng, L., ed., Marine Insects. North Holland, Amsterdam. 581 p.

\section{LITERATURE CITED}

Adams, D. A. 1963. Factors influencing vascular plant zonation in North Carolina salt marshes. Ecology 44: 44556.

Becker, P. 1961. Observations on the life cycle and immature stages of Culicoides circumscriptus Kieffer (Diptera: Ceratopogonidae). Proc. Roy. Soc. Edinb. (B)67: 363-86.

Broome, S. W., W. W. Woodhouse \& E. D. Seneca. 1973. An investigation of propogation and the mineral nutrition of Spartina alterniflora. Univ. of North Carolina Sea Grant Program, Publication UNC-SG-74-14.

Cameron, G. N. 1972. Analysis of insect trophic diversity in two salt marsh communities. Ecology 53: 58-73.

Chapman, V. J. 1960. Salt marshes and salt deserts of the world. Leonard Hill (Books) Ltd., London. 392 p.

Cooper, A. W. 1974. Salt marshes. p. 55-98. In: Odum, H. T., B. J. Copeland \& A. McMahan, eds., Coastal ecological systems of the United States. Vol. 2. The Conservation Foundation, Washington, D.C. 521 p.

Davies, J. B. 1966. An evaluation of the emergence or box trap for estimating sandfly (Culicoides: Heleidae) populations. Mosquito News 26: 69-72.

Dove, W. E., D. G. Hall \& J. B. Hull. 1932. The salt marsh sand fly problem. Ann. Ent. Soc. Amer. 25: 505-22.

Dukes, J. C., T. D. Edwards \& R. C. Axtell. 1974. Distribution of larval Tabanidae (Diptera) in a Spartina alterniflora salt marsh. J. Med. Ent. 11: 79-83.

Forratini, O. P., E. X. Rabello \& D. Pattoli. 1958. Culicoides do região neotropical (Diptera: Ceratopogonidae). IIObservacões sôbre biologia em condicões naturalis. Arquiv. Fac. Hig. Saúde Púb. Univ. São Paulo 12: 1-52.

Hair, J. A., E. C. Turner, Jr \& D. H. Messersmith. 1966. Larval habitats of some Virginia Culicoides (Diptera: Ceratopogonidae). Mosquito News 26: 195-204.

Jamnback, H. 1965. The Culicoides of New York State (Diptera: Ceratopogonidae). N.Y. St. Mus. Sci. Serv. Bull. 399. $154 \mathrm{p}$.

Jamnback, H., W. Wall \& D. L. Collins. 1958. Control of Culicoides melleus (Coq.) (Diptera: Heleidae) in small plots, with brief descriptions of the larvae and pupae of two coastal Culicoides. Mosquito News 18: 64-70.

Jones, R. H. 1961. Observations on the larval habitats of some North American species of Culicoides (Diptera: Ceratopogonidae). Ann. Ent. Soc. Amer. 54: 702-10.

Kettle, D. S. 1951. The spatial distribution of Culicoides impunctatus Goet. under woodland and moorland conditions and its flight range through woodland. Bull. Ent. Res. 42: 239-91.

Kettle, D. S. \& J. W. H. Lawson. 1952. The early stages of British biting midges Culicoides Latreille (Diptera: Ceratopogonidae) and allied genera. Bull. Ent. Res. 43: 421-67.

Kline, D. L. \& R. C. Axtell. 1975. Culicoides melleus (Coq.) (Diptera: Ceratopogonidae): Seasonal abundance and emergence from sandy intertidal habitats. Mosquito News 35: $328-34$.

1976. Salt marsh Culicoides (Diptera: Ceratopogonidae): Species, seasonal abundance and comparison of trapping methods. Mosquito News 36: 1-10.

Kline, D. L., J. C. Dukes \& R. C. Axtell. 1975. Salt marsh Culicoides (Diptera: Ceratopogonidae): Comparison of five common larval sampling methods. Mosquito News 35: $147-50$.

Kraeuter, J. N. \& P. L. Wolf. 1974. The relationship of marine macroinvertebrates to salt marsh plants. p. 449-62. In: Reimold, R. \& W. H. Queen, eds., Ecolog y of Halophytes. Academic Press, New York \& London. 605 p.

Linley, J. R. 1968. Colonization of Culicoides furens. Ann. Ent. Soc. Amer. 61: 1486-90.

Linley, J. R. \& J. B. Davies. 1971. Sandflies and tourism in Florida and the Bahamas and the Caribbean area. $J$. Econ. Ent. 64: 264-78.

Linley, J. R., F. D. S. Evans \& H. T. Evans. 1970. Seasonal emergence of Culicoides furens (Diptera: Ceratopogonidae) at Vero Beach, Florida. Ann. Ent. Soc. Amer. 63: 1332-39.

Ranwell, D. S. 1972. Ecology of salt marshes and sand dunes. Chapman \& Hall, London. 258 p.

Rogers, A. J. $\quad$ 1962. Effects of impounding and filling on the production of sand flies (Culicoides) in Florida salt marshes. J. Econ. Ent. 55: 521-27.

Service, J. 1972. A user's guide to the statistical analysis system. Student Supply Stores, North Carolina State University at Raleigh. 260 p.

Wall, W. J., Jr. 1973. The intertidal sand and salt marsh invertebrate fauna associated with the blcodsucking Diptera of Cape Cod, Massachusetts. Environ. Ent. 2: 681-84.

Wall, W. J. \& O. W. Doane, Jr. 1960. A preliminary study of the bloodsucking Diptera on Cape Cod, Massachusetts. Mosquito News 20: 39-44.

Williams, R. W. 1957. Observations on the breeding habitats of some Heleidae of the Bermuda Islands (Diptera). Proc. Ent. Soc. Wash. 59: 61-66.

1961. Parthenogenesis and autogeny in Culicoides bermudensis Williams. Mosquito News 21: 116-17.

1964. Observations on habitats of Culicoides larvae in Trinidad, W.I. (Diptera: Ceratopogonidae). Ann. Ent. Soc. Amer. 57: 462-66.

Wyatt, I. J. 1961. Pupal paedogenesis in the Cecidomyiidae (Diptera). Proc. Roy. Ent. Soc. Lond. (A) 36: 133-43. 